\title{
DECISION SUPPORT WHEN CONFIGURING AUTOMATIC SYSTEMS
}

\author{
Magnus Sjöberg \\ Ph. D. Student, Dept. Of Production Engineering, Royal Institute of Technology, \\ magnus.sjoberg@iip.kth.se,SWEDEN
}

\begin{abstract}
Automatic systems are used to varying extent within the manufacturing industry. The challenge is to find the most advantageous applications of automation to the manufacturing system over time. Enquiries concerning automation appear when configuring or re-configuring the manufacturing system. The objective of this paper is to describe and to evaluate existing methods that can be used as decision support when deciding on automation. A participating study was conducted within an automation project. The work procedures within the industry are often based on experience and not on systematic methods. Outgoing from these methods and industrial experience a frame work for a new method is suggested. Issues that are critical to a useful and applicable decision method are pinpointed and discussed.
\end{abstract}

\section{INTRODUCTION}

The automation issues are a subset of the configuring of manufacturing/assembly systems, and depending on to what extent, the issues are more or less complex. Configuring or re-configuring a manufacturing system is a many-sided undertaking. The configuring process involves many decisions and engineering tasks to be carried out. Often the tasks are coupled and entail multidisciplinary problems. Depending on the product and the volumes the automation solution might be more or less given. It is said, when investing in technique, that there are only three questions that need to be answered:

- What does the technique do?

- How much does it cost?

- What is the reliability in the answer of the first two questions?

These questions are very unspecific and arbitrary and to be able to answer the questions they must be divided into more precise questions. The first question, what does the technique do? can be divided into: What are the abilities and capabilities? What other techniques can be used? Manual or hybrid solutions? How does it affect the system according to system parameters such as cost, quality, delivery and flexibility. The second question, how much does it cost? can be divided into: Shortor long term costs/earnings? Intangible/tangible costs/earnings? The third question, what is the reliability in the answer of the first two questions? can be divided into: Questions concerning empirical data? Routine? Simulation? Still these questions are not easily answered. The use of methods and decision supports, enable a systematic way to determine the problems. Decision support tools is in this paper a 
collective term for all concepts with the intention to facilitate the work procedure, when making decision on automation. In this paper the objectives have been to collect and review representative decision supports that are available for engineers concerned with these issues, to suggest a framework for a new method, and to discuss critical issues within this area. No distinction between parts manufacturing and assembly has been made. To a certain level the issues concerned can be seen as common for both assembly and parts manufacturing. This paper is based on a litterateur survey and on a participating study. The ambition has been to cover the different decision support tools, categorise and to analyse them outgoing from user preferences. The literature survey contains sub chapters where different representative decision support tools are described and discussed. The participating study took place at a company, a major producer of robots. The project was conducted within their own manufacturing. The purpose of the project was to enable automatic assembly, for a sub assembly system. Their work procedure was examined. The study serves as start of collecting empirical data of industrial use of decision supports.

\section{LITERATURE SURVEY}

The survey covers representative samples of different decision support tools. Approximately 100 papers were considered and 17 papers were sorted out and further analysed. The different support tools are divided into the categories: Methodologies, methods, check lists and thumb rules. Further they are described and analysed. Some of the support tools refer to a system solution and others to specific process solutions. Methodologies should be seen as a scientific and systematic work procedure, methods are often included in methodologies. Methods are more specific in their tasks and are often represented by a model, a selection schema or a logically structured diagram. Check 1 ists a nd thumb rules a re, a s their $n$ ame implies, more vague and arbitrary. Automatic systems and automated solution within manufacturing and assembly have huge variations and there is no uniform categorisation and nomenclature. In this paper a division between system applications and single process applications is made. User preferences are in this paper defined as the value of using the decision support. What comes out from using the method; how much effort is needed to get relevant answers, what is the accuracy of the answer?

\subsection{Design methodologies}

The methodologies analysed in this paper are not of the same character as for example reaserch methodologies, but more of methods with substantial context.

There are some different manufacturing system design methodologies, and parts of them treat the aspects of deciding what process technique to use. The first

\footnotetext{
${ }^{\mathrm{i}}$ The papers were collected from the databases: Emerald, Science Direct and ISI.
} 
methodology discussed, Figure 1 (Rao and $\mathrm{Gu}, 1997$ ) is presented as a manufacturing system design methodology. The methodology is a top down approach where the first step is requirements of the manufacturing sy stem design and the last steps are evaluation and reconfiguration. The steps; selection and design of machines and design of manufacturing system configuration, briefly declare what issues are to be determined, but not how they should be managed and accomplished. Abdel-Malek et al (2000), describes similar system design methodologies, but with different focus, for instance on flexibility or simulation.

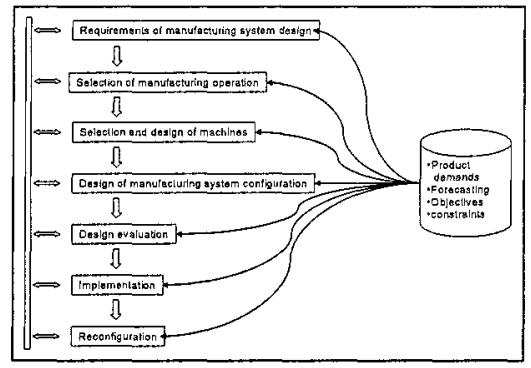

Figure 1. Manufacturing system design methodology (Rao and $\mathrm{Gu}, 1997$ )

The methodology described by Borenstein et al (1999) is concerned with selection and comparing between different system configurations and alternatives, Figure 2. The principles which this methodology is based on are:

- Strategy based analysis

- Systemic analysis

- User centred analysis

- Interdisciplinary analysis

As in the previous methodology described, this is a top down approach. The methodology describes all steps in detail and the issues concerned. The above principles from which the methodology is developed, give a strategic perspective instead of a strictly financial which is very common (Burcher, Lee, 2000). Simulation is a requirement to facilitate use of the methodology, and is suggested in other similar methodologies (Pflughoeft et al 1996). There has been considerable research within the area of FMS decisions. Many researchers have considered the issues and decisions about flexibility and the often large investment required to implement these systems.

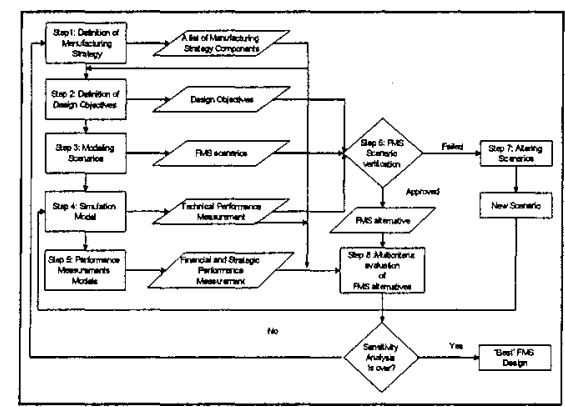

Figure 2. Design methodology for FMS-systems (Borenstein, Becker, Santos, 1999) 
Some methodologies do not primarily focus on automation issues, but is more to be seen as the context in which the decision on automation is taking place. The methodologies provide a holistic perspective and a project approach for which they are useful. The focus is mainly on system solutions. However none of the methodologies that have been examined have dealt with the primary issue, whether to automate or not. Often that decision is assumed and approved. It is difficult to evaluate from a user perspective. Methodologies like the above described serve as important project guidance.

\subsection{Methods}

Methods focus on more specific tasks. The one described below (Boubkri and Nagaraj, 1993) delivers answers to what kind of automation to use, in terms of dedicated or programmable. The factors on which the schema is based are:

1. Annual number of end products

2. Number of variants of the product

3. Life cycle of the product

4. Number of parts in the product

The annual number of products is important when deciding on assembly techniques. Robotic systems play an important roll in some volume ranges. In other there are no economic competitors to manual assembly.

Dedicated automatic assembly emerge where there are large volumes and few variants or single variant production. Thus there is a large span where dedicated systems do not fit the wanted solution. As the number of models increase the demands can not be met by dedicated assembly systems. It is in this range that flexible systems are most feasible. Life cycle of the product also affects the system requirements.

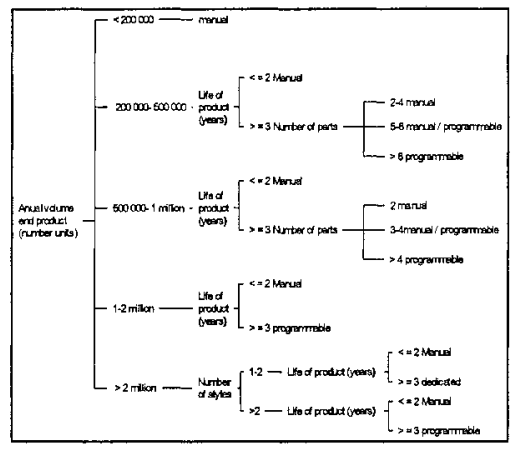

Figure 3. Selection schema (Boubkri and Nagaraj, 1993)

The sum of key indicators; annual number of end products, number of models of the product, life cycle of the product, and number of parts in the product are essential when deciding on what attributes that are important in this selection schema. 
This selection method might be useful to give an indication, but it lacks some important aspects. It is not dynamic, and does not consider the changes of technique and cost. Modularisation of the system i.e. system flexibility, is not considered. Due to this the accuracy of methods like this, is changing as function of time. The assembly systems are getting more technically advanced i.e. are capably of managing more tasks, faster and with a higher quality. Further this schema is based on economic assumptions such as short payback times, and lacks the aspects of strategic thinking. The focus is on system solutions.

\subsection{Check lists and thumb rules}

Checklist and thumb rules are, as their name implies, arbitrary and can be seen as complements to methodologies and methods. What they do is also to pinpoint critical issues but they do not provide any technical solutions. Managers who make automation decisions must consider the following factors (Norman and Frazier, 1999):

1. Economic factors

2. Effects on market share

3. Effects on product quality

4. Effects on manufacturing flexibility

5. Effects on labour relations

6. The amount of time required for implementation

7. Effects of automation implementation on ongoing production

8. Amount of capital required

When making decisions concerning in which processes to invest, companies need to satisfy both technical and business perspectives. According to Hill (1995) the following issues have to be considered when configuring the manufacturing system.

1. Decide on how much to buy from outside the company, which in turn, determines the make-in task.

2. Identify the appropriate engineering-technology alternatives to complete the task embodied in each product. This will concern bringing together the make-in components with the bought out items to produce the final product specification at agreed levels of quality.

3. Choose between alternative manufacturing approaches to complete the task embodied in providing the products involved. This will need to reflect the market in which the product competes and the volumes associated with those sales.

Technology alternatives and manufacturing alternatives include the selection of automation technique. The guidance is that it should correlate to the business objectives.

These checklists serve as input to discussions and further analysis. The first list mentioned does not consider the solution as a strategic resource. Without a strategic perspective the issues do often end up in how to evaluate non monetary values. In such cases there can be a risk to overestimate values that easily can be transformed into payoff calculations etc. 
Thumb rules that are common when reasoning on automation are:

- If a machine/robot replaces two employees, then it might be economically justifiable

- Does the investment have a payback time shorter than one year, then it's acceptable

This argumentation and thinking are used within industry. The reasoning in terms of replacing employees with machines is essential when deciding on automation, though this thumb rules do exclude many aspects and render a short term economic perspective. Strategic benefits are not considered. Unfortunately these examples are common argumentation within the industry. However they do reflect the environment where the industry exists.

\section{PARTICIPATING STUDY}

The purpose of the project was to enable automatic assembly, for a sub assembly cell. The work procedure of developing the cell was examined, and serves as start of collecting empirical data, of the industrial use of decision supports.

Conclusions so far is that in this specific case, some decision supports for automation were used and they sort under the category thumb rules. The work procedure was following a project agenda. The project was very well defined, i.e. objective, time and cost were clearly defined. However, much of the work of designing the cell and convert sy stem $r$ equirements to $c$ ell a bilities was $b$ ased on skilled and experienced personnel. Further the study indicates the need for systematic work procedures such as decision methods. However more studies must be conducted to give relevant input of specific industry requirements on such methods.

\section{SUGGESTED FRAMEWORK FOR A NEW DECISION METHOD}

A decision method that aims at facilitating decision on automation involves three main areas of different kind:

1. The strategic area where the manufacturing/assembly system is seen as a facilitator of the business strategy.

2. Technical aspects of automation- and manufacturing/assembly system practice.

3. Decision making which involves managerial and communication issues.

The strategic area is of outmost importance since investments in automation technology often end up in justification reasoning. The company must see their production system as an enabler of their business strategy (Skinner, 1969).

The second area: The technology is under constant change and development. Therefore the method must be able to handle these dynamic changes. Strategic and successful production systems depend on many factors. The decision method must 
correlate to other production system design issues. The hierarchy, and whether the decision on automation is subordinated to other design issues or not, depends on the situation and context. This must also be considered. Often the third area is neglected, though it is not of less importance. The engineering / production development staff (PDS) must be able to communicate and get acceptance of his / their suggestions. That is both internal engineer-PDS, and external PDS-managerial level. A basic condition for high-quality solutions within the manufacturing/assembly system is knowledge and acceptance at all concerned levels within the company. These a re the corner s tones on which the method should be based upon. To be able to communicate and generalize the method there must be a structured and well defined taxonomy and categorisation of automation systems. An approach where the strategic requirements and the system capabilities and abilities are mapped is one way to cover that issue.

\section{CRITICAL ISSUES}

Automation affects many system parameters and the causalities are hard to detect. This tends to a myopic reasoning and exclusion of important aspects. Aspects that affect and are hard to include in common methods are:

1. Life cycle of the product

2. Life cycle of the production system

3. Flexibility (dynamic capability)

4. Non economic and intangible effects

5. Short time economic results dominates the company structure and their way of acting

6. Long time planning is less accurate than short time planning

The concern within industry often is that automation and the implication from the technology involved is no issue, as long as there is a sufficient pay back of the investment. What is considered as sufficient pay back time differs, depending of the situation and company. Thus they might exclude strategic benefits. Strategic benefits are concerned with increased risks. Solutions on automation require a strategic perspective and the industry lacks strategic and systematic work procedures (Axelson et al, 2004). Manufacturing strategy definition, strategy links to competitive priorities (Garvin, 1993) and automation decisions are areas where it is hard to find substantial support. Automation is a wide term. Classification and nomenclature a re issues mentioned in this $p$ aper. This is a $n$ i ssue $c$ oncerned with generalisation and appliance of methods. Taxonomy (Bourgeois, et al, 2002), the focus is on assembly and consequently it does not cover other areas.

\section{CONCLUSIONS}

The methodologies and the category thumb rules and checklists have some common aspects. Neither of them aim towards specific solutions Therefore are more feasible for a wider range of applications. The methodologies examined lacks in the 
argumentation for the trade off that has to be made and in the support for the decision. A method often supports a certain kind of decision and is therefore delimited in its application area. Generally one can say that methodologies and checklists sustain more accurate over time, and that methods tend to have shorter life cycles due to the level of specific factors considered. This survey indicates that there is a need for decision methods within industry. This is also concluded in a study conducted within Swedish industry (Axelson et al, 2004).

\section{REFERENCES}

1. A bdel-Malek L, D as S. K., Wolf C. (2000), "Design and implementation of flexible m anufacturing solutions in agile enterprises" International Journal of Agile Management Systems, Vol. 2 No. 3, pp. 187-195.

2. Borenstein D., Becker J. L., Santos E. R. (1999), “A systematic and integrated approach to flexible manufacturing system design", Integrated Manufacturing Systems, Vol. 10 No 1, pp. 6-14.

3. Bourgeios F., Chiabra Z., Muth A., Neri F., Onario M., Santochi M., (2002) Assembly Net Taxonomy and Glosary, Assembly-Net Consortium.

4. Burcher P. G., Lee G. L. (2000) "Competitiveness strategies and AMT investment decisions" Integrated Manufacturing System. Vol. 11 No. 5, pp. 340-347

5. Boubkri N and Nagaraj S (1993), "An Integrated Approach for the Selection and Design of Assembly Systems", Integrated Manufacturing System. Vol. 4 No. 1, pp. 11-17

6. Garvin, D.A (1993), "Manufacturing strategic planning", California Management Review, Vol.35 No.

4, pp. 85-106.

7. Hill, T (1995), 'Manufacturing strategy Text and Cases", Palgrave, New York

8. Norman and Frazier (2002), Operations Management, Southwestern college publishing, 2002, 9th Edition.

9. Pflughoeft K. A., Hutchinson G. K., Nazareth D. L., (1996) "Intelligent decision support for flexible manufacturing: Design and Implementation of a knowledge-based simulator", International Journal of Management Science, Vol. 24, No. 3, pp. 347-360

10. Rao H. A. and Gu P. (1997), "Design methodology and integrated approach for design of manufacturing systems", Integrated Manufacturing Systems, Vol. 8 No 3, pp. 159-171.

11. Skinner W. (1969),"Manufacturing - missing link in corporate strategy", Harvard Business Review, May-June, pp.136-45

12. Axelson D. et al, (2004) Woxénrapport no 39 ISSN 1650-1888 